University of Nebraska - Lincoln

DigitalCommons@University of Nebraska - Lincoln

April 2007

\title{
Observer Bias in Anuran Call Surveys
}

\author{
Aaron Lotz \\ University of Nebraska-Lincoln \\ Craig R. Allen \\ University of Nebraska - Lincoln, callen3@unl.edu
}

Follow this and additional works at: https://digitalcommons.unl.edu/usgsstaffpub

Part of the Earth Sciences Commons

Lotz, Aaron and Allen, Craig R., "Observer Bias in Anuran Call Surveys" (2007). USGS Staff -- Published Research. 13.

https://digitalcommons.unl.edu/usgsstaffpub/13

This Article is brought to you for free and open access by the US Geological Survey at DigitalCommons@University of Nebraska - Lincoln. It has been accepted for inclusion in USGS Staff -- Published Research by an authorized administrator of DigitalCommons@University of Nebraska - Lincoln. 


\title{
Observer Bias in Anuran Call Surveys
}

\author{
AARON LOTZ, ${ }^{1}$ Nebraska Cooperative Fish and Wildlife Research Unit, School of Natural Resources, University of Nebraska, Lincoln, NE 68583, USA \\ CRAIG R. ALLEN, United States Geological Survey-Nebraska Cooperative Fish and Wildlife Research Unit, School of Natural Resources, University of \\ Nebraska, Lincoln, NE 68583, USA
}

\begin{abstract}
Amphibian monitoring programs rarely question the quality of data obtained by observers and often ignore observer bias. In order to test for bias in amphibian call surveys, we sampled 29 clusters of wetlands from the Rainwater Basin, Nebraska, USA, totaling 228 functionally connected wetlands. Sampling consisted of 3-minute stops where volunteers recorded species heard and made digital recordings. Based on 627 samples, we examined 3 types of observer bias: omission, false inclusion (commission), and incorrect identification. Misidentification rates ranged from $4.2 \%$ to $18.3 \%$. Relatively high and unquantified error rates can negatively affect the ability of monitoring programs to accurately detect the population or abundance trends for which most were designed. (JOURNAL OF WILDLIFE MANAGEMENT 71(2):675-679; 2007)
\end{abstract}

DOI: $10.2193 / 2005-759$

KEY WORDS amphibians, anuran call surveys, monitoring, observer bias, rainwater basin, wetlands.

Amphibian declines in recent decades have spurred the initiation of amphibian monitoring programs throughout the world (Blaustein et al. 1994, McDiarmid and Donnelly 1994, Buckley and Beebee 2004, Schmidt 2005). Road-based surveys of calling males may provide an adequate method to monitor trends in amphibian populations (Scott and Woodward 1994). In 1994 the North American Amphibian Monitoring Program was created in an effort to standardize methodologies and investigate monitoring needs (Mossman et al. 1998). State-run, long-term monitoring programs include those in Michigan (Skelly et al. 2003), Wisconsin (Mossman et al. 1998), Iowa (Hemesath 1998), and Nebraska, USA (M. Fritz, Nebraska Game and Parks Commission, personal communication). Different types of observer bias are documented in bird-density call surveys and are reported to be high (Bart and Schoultz 1984, Sauer et al. 1994, McLaren and Cadman 1999). Observer bias in amphibian call surveys is not well-documented.

Hemesath (1998) noted 4 main problems in call survey data: 1) incomplete surveys, 2) surveys sometimes conducted under inappropriate weather and time conditions, 3) errors in identification, and 4) inter-observer variability. Studies have investigated species detectability (MacKenzie et al. 2002, Pierce and Gutzwiller 2004, Pellet and Schmidt 2005), inter-observer variation (Bishop et al. 1997, Shirose et al. 1997, Kline 1998, Wear et al. 2002) and multiple sampling methods (Pearman et al. 1995, Parris et al. 1999, Corn et al. 2000, Paszkowski et al. 2002, Funk et al. 2003) in anuran call surveys. However, observers may fail to detect all species present, falsely include species not actually present, or incorrectly identify calls of species resulting in inaccurate assessments of anuran populations. Most anuran call survey studies fail to mention observer error (Kolozsvary and Swihart 1999, Lehtinen et al. 1999, Pope et al. 2000, Zampella and Bunnell 2000, Crouch and Paton 2002) or mention possible observer error or other forms of bias but do not document it (Vandewalle et al. 1996, Stevens et al.

${ }^{1}$ E-mail: drlotz@bigred.unl.edu
2002), thus producing results with unknown utility. The lack of documentation of observer bias in anuran call surveys is further complicated by reanalysis of other investigators' call survey data for publication (e.g., Knutson et al. 1999, Sargent 2000, Trenham et al. 2003).

Genet and Sargent (2003) addressed observer bias in anuran call surveys. They sent an audio compact disc (CD) with 12 tracks (each representing a typical wetland breeding site) to 179 volunteers in the Michigan Frog and Toad Survey (MFTS). Each track was 5 minutes in length (MFTS listening-time protocol) and each volunteer was asked to record species present in the recording. Genet and Sargent (2003) reported that $40 \%$ of volunteers could not identify all the species correctly, and on half of the 12 tracks volunteers missed or incorrectly identified species. However, the use of audio CDs does not capture field conditions and may underestimate bias. To assess the accuracy of amphibian call counts in the field, we established a monitoring protocol for amphibians in the Rainwater Basins of Nebraska and documented observer bias.

\section{STUDY AREA}

The Rainwater Basin region was located in south-central Nebraska and occupied over one million hectares in 17 Nebraska counties. Rainwater Basin wetlands are critical to the 8 frog and toad species that resided in the region (bullfrog [Rana catesbeiana; nonindigenous], great plains toad [Bufo cognatus], northern cricket frog [Acris crepitans], plains leopard frog [Rana blairi], plains spadefoot [Spea bombifrons], Cope's gray treefrog [Hyla chrysoscelis], western chorus frog [Pseudacris triseriata], Woodhouse's toad [Bufo woodhousii]). Although not well-documented in early literature, the Rainwater Basin wetlands may have represented an important area of reproductive and adult habitat for amphibians prior to extensive land conversion for crop production.

\section{METHODS}

We sampled 15 clusters of wetlands from the western and 14 clusters from the eastern portions of the Rainwater Basin, 
consisting of 228 (western total: $n=83$ and eastern total: $n=$ 145) wetlands. We split the Basin because of marked differences in environmental conditions (i.e., the eastern basin received substantially more precipitation). A cluster of wetlands varied from one (i.e., an isolated wetland without functional connectivity) to many wetlands. We chose wetland clusters by randomly selecting a National Wetland Inventory (NWI) polygon and including all wetlands that were functionally connected (Keitt et al. 1997) to the chosen wetland. Functional connectivity is a measure of patch connectivity specific to the potential movement and dispersal of individuals within a species. Amphibian movements were poorly documented, so we used a distance of 3 $\mathrm{km}$, based on an average of known movements for similar larger amphibian species (Miaud et al. 2000, Muths 2003). Within each 3-km buffer, we selected wetlands based on the intersection of NWI polygons and a historical hydric soil Geographic Information Systems layer provided by the Nebraska Game and Parks Commission, in a manner similar to the methods employed by Munger et al. (1998).

We sampled all wetlands within a cluster during a single sampling period. We sampled each wetland 3 times from 12 May to 7 August 2005 to account for differing calling phenologies among species. We trained 13 observers in a 1day workshop to explain protocol and expose observers to calls of anurans present in the Rainwater Basin, and we provided each observer digital recordings of those species. Observers were either full-time professional biologists with advanced degrees (experienced, $n=4$ ) or temporary biological technicians with bachelor's degrees (novice, $n=$ 9). Sampling began 0.5 hours after sunset and observers listened for and recorded amphibian calls for 3 minutes following an initial 2-minute acclimation period (similar to the method of Goldberg and Schwalbe 2004). Surveys were conducted by one observer from the side of a county road at each wetland within a cluster (Shirose et al. 1997, Pierce and Gutzwiller 2004). We used hand-held digital sound recorders (Model DM-10; Olympus, Center Valley, PA) to record calls. We preinstalled on each recording device digital audio samples of each potential species present as well as an audio sample of the American toad (Bufo americanus). The American toad is not known to be in this region (Conant and Collins 1998) and novice observers did not know this. We conducted surveys when there was little or no rain, wind was minimal (Beaufort scale $<4$ ), and air temperature was $>5^{\circ} \mathrm{C}$ (Stevens and Paszkowski 2004).

We collected 248 samples in the western basin, including 117 where no amphibians were heard by the observer, and 379 samples in the eastern basin, including 229 where no amphibians were heard by the observer. We examined 3 types of mutually exclusive potential observer bias: omission, commission, and incorrect identification. Omission occurred when a species was heard on the audio recording but was not recorded on data sheets by the field observer. Commission occurred when a species was recorded on data sheets by the field observer but was not heard on the audio recording. Incorrect identification occurred when a particular species was recorded on data sheets by the field observer but a different species was heard on the audio recording. The authors listened to most recordings once. However, samples $(n=35)$ that were questionable were listened to multiple times and verified by an independent expert. We assessed bias in 2 ways to obtain conservative and less conservative estimates. We based conservative assessments on all samples, including those where observers recorded no amphibians. We based less conservative assessments only on samples where $\geq 1$ calling amphibian was recorded by an observer. We compared all 3 types of bias between experienced and novice observers using 2-sample $t$-tests (SAS Institute 1999). For each type of observer bias, we calculated average error rate for each observer.

To ascertain the effects of observer bias on the estimation of proportion of area occupied by any given species, we used program PRESENCE (Proteus Wildlife Research Consultants, Dunedin, New Zealand; MacKenzie et al. 2002). Program PRESENCE corrects for variability in species dectectability, another important source of error in amphibian sampling. We examined 5 contrasts in program PRESENCE. Contrast 1 had observer commission, omission, and misidentification errors uncorrected. Contrast 2 had omission and misidentifications corrected but commission errors were uncorrected. Contrast 3 had misidentification errors corrected but omission and commission errors were uncorrected. Contrast 4 had commission and misidentification errors corrected but omission errors were uncorrected. Contrast 5 had commission errors corrected but omission and misidentification errors were uncorrected. Experience level comparisons and PRESENCE data analyses were based on all samples.

\section{RESULTS}

Of our samples, $1.2 \%$ (western basins) and 1.8\% (eastern basins) had species not recorded on data sheets but audible to the authors on recordings (omission errors). Woodhouse's toad in the western basin and Cope's gray treefrog and western chorus frog in the eastern basin were the most commonly omitted species. Considering only samples that included $\geq 1$ species heard by the field observer, $2.3 \%$ in the western basin and $4.7 \%$ in the eastern basin had omission error (Fig. 1).

Of our samples, 19\% (western basin) and 23.8\% (eastern basin) included species that were not audible on recordings (commission errors). In the western basin, Woodhouse's toad, western chorus frog, and American toad were the species most commonly heard by observers that were not audible on recordings (accounting for $18.5 \%, 16.8 \%$, and $16.8 \%$, respectively, of the total commission error). In the eastern basin, the plains leopard frog and bullfrog were the species most commonly heard by observers that were not audible on recordings $(40.5 \%$ and $19.5 \%$, respectively, of the error). The American toad was recorded by observers as present (heard) on $1.3 \%$ of surveyed wetlands in the eastern basins, although this species does not occur in this region of Nebraska and was not apparent on recordings. Considering 

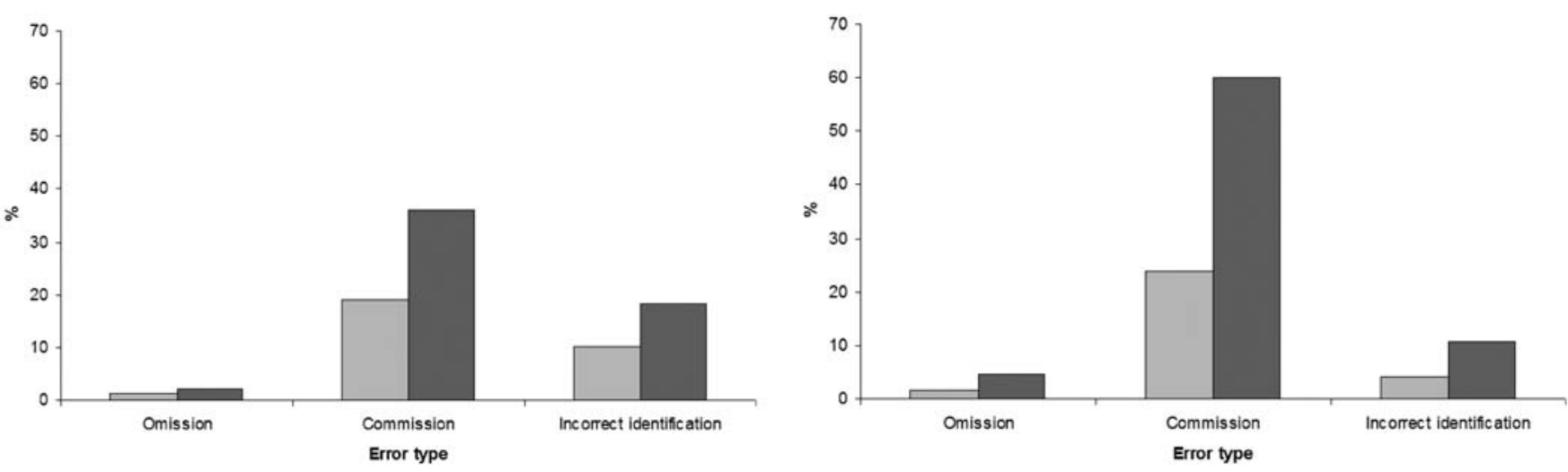

Figure 1. Omission, commission, and incorrect identification error rates from surveys conducted between 12 May and 7 August 2005 in the western and eastern portions of the Rainwater Basin of Nebraska, USA. Light bars represent a conservative assessment of bias based on all samples, including those where observers recorded no amphibians. Dark bars represent a less conservative assessment, based only on samples where $\geq 1$ calling amphibian was recorded.

only samples that had $\geq 1$ species heard by the field observer (i.e., a less conservative assessment of error rates) $35.9 \%$ of samples in the western basin and $60.0 \%$ in the eastern basin had $\geq 1$ commission error (Fig. 1). Of the observers that only noted one species calling $(n=111)$, no species were heard on $34.2 \%$ of those recordings.

Of our samples, $10.1 \%$ and $4.2 \%$ in the western and eastern Rainwater Basin, respectively, had incorrectly identified species. In both portions of the Rainwater Basin, the most commonly misidentified species was the cricket (Gryllidae spp.), which was recorded by observers as the northern cricket frog (accounting for 55.4\% and 50.0\% of the error in the western and eastern basins, respectively). In the western basin, Woodhouse's toad was incorrectly identified as the Great Plains toad and the western chorus frog as Cope's gray treefrog. In the eastern Basin, the plains spadefoot was incorrectly identified as either a western chorus frog or Cope's gray treefrog. One Great Plains toad call was mistaken as an American toad call. Considering only samples that had $\geq 1$ species heard by the field observer, $18.3 \%$ in the western basin and $10.7 \%$ in the eastern basin had $\geq 1$ incorrect identification error (Fig. 1).

There were no significant differences between experienced and novice observers in omission $(t=0.36, \mathrm{df}=11, P=$ $0.723)$, commission $(t=0.132, \mathrm{df}=11, P=0.897)$, and incorrect identification $(t=0.086, \mathrm{df}=11, P=0.933)$ error rates. Novice observer error rates were as high as $20 \%$ in omission error, $31 \%$ in commission error, and $45 \%$ in incorrect identification (experienced observer; 8\%, 31\%, and $31 \%$, respectively). Correcting and contrasting the different forms of observer bias affected the estimation of proportion of area occupied for a species by as much as 10 times. However, the direction of the change varied among contrasts and was not predictable. The lowest occupancy estimates were generally where species were removed from the data set due to commission errors (Table 1).

\section{DISCUSSION}

Commission error was the greatest observer bias documented, but commission errors in this study must be interpreted with caution. Recordings sometimes failed to detect species that were present and calling; thus, our assessment of apparent commission error overestimates actual commission. Omission error was the lowest bias documented, but omission errors were underestimated for the same reasons that commission errors were overestimated. Thus, we conducted 2 forms of analysis that may help bound the actual error rates. Environmental noise (mainly irrigation pumps and wind gusts), calls of the western chorus frog (i.e., choruses tended to saturate and drown out calls of other species), and the faint calls of some species (e.g., plains leopard frog) were all factors that potentially impeded the performance of the digital handheld recorders. Similar types of noise in anuran call surveys are not uncommon (Parris et al. 1999, Corn et al. 2000). In Nebraska, irrigation pump noise increased during the course of this study because irrigation needs increase during the summer and irrigated crops are ubiquitous in the Rainwater Basin.

Experience level had little or no impact on the amount of error associated with each observer, but this may be because there was little difference in actual field anuran-call-survey experience between professional biologists and the biological technicians. This was similar to results in other amphibian call-survey studies that analyzed observer bias (Shirose et al. 1997, Genet and Sargent 2003). There were no clear trends in the effects of observer bias on occupancy estimates; however, the effects were often substantial. Most types of observer bias decrease as observers become more experienced in the identification of anuran or bird calls (Sauer et al. 1994, Shirose et al. 1997, McLaren and Cadman 1999, Wear et al. 2002). A decrease in error rates was not present during our study, however. A decrease in observer bias over time suggests that most types of observer error may 
Table 1. Program PRESENCE estimated occupancy rates (Est.) and standard errors based on 5 observer bias contrasts from surveys conducted between 12 May and 7 August 2005, in western and eastern portions of the Rainwater Basin, Nebraska, USA. There was insufficient data to conduct some contrasts for some species.

\begin{tabular}{|c|c|c|c|c|c|c|c|c|c|c|}
\hline \multirow[b]{2}{*}{ Species } & \multicolumn{2}{|c|}{ Contrast $1^{a}$} & \multicolumn{2}{|c|}{ Contrast $2^{b}$} & \multicolumn{2}{|c|}{ Contrast $3^{c}$} & \multicolumn{2}{|c|}{ Contrast $4^{\mathrm{d}}$} & \multicolumn{2}{|c|}{ Contrast $5^{\mathrm{e}}$} \\
\hline & Est. & SE & Est. & SE & Est. & SE & Est. & SE & Est. & SE \\
\hline Western chorus frog & 0.700 & 0.056 & 0.763 & 0.056 & 0.748 & 0.057 & 0.752 & 0.081 & 0.672 & 0.076 \\
\hline Woodhouse's toad & 0.784 & 0.106 & 0.653 & 0.064 & 0.679 & 0.074 & 0.557 & 0.068 & 0.663 & 0.104 \\
\hline Cope's gray treefrog & 0.763 & 0.383 & 0.275 & 0.067 & 0.331 & 0.103 & 0.115 & 0.033 & 0.444 & 0.270 \\
\hline Plains leopard frog & & & 0.572 & 0.147 & 0.567 & 0.157 & 0.348 & 0.193 & 0.348 & 0.193 \\
\hline Plains spadefoot & 0.535 & 0.343 & & & & & 0.073 & 2.844 & 0.228 & 0.139 \\
\hline Northern cricket frog & 0.487 & 0.290 & 0.958 & 0.888 & & & 0.035 & 1.372 & & \\
\hline
\end{tabular}

${ }^{a}$ Contrast 1 had observer commission, omission, and misidentification errors uncorrected.

${ }^{\mathrm{b}}$ Contrast 2 had omission and misidentifications corrected but commission errors were uncorrected.

${ }^{c}$ Contrast 3 had misidentification errors corrected but omission and commission errors were uncorrected.

${ }^{\mathrm{d}}$ Contrast 4 had commission and misidentification errors corrected but omission errors were uncorrected.

${ }^{\mathrm{e}}$ Contrast 5 had commission errors corrected but omission and misidentification errors were uncorrected.

eventually diminish over multi-year studies, but that is contingent on the ability to retain the same observers, removal of field observers with initially high bias, consistently adhering to sampling and listening protocol, administration of quality-control surveys, and more intensive training workshops.

Studies comparing multiple sampling methods of anuran populations have been inconclusive and all suggest that no single method alone will satisfy all the requirements of a valid study (Pearman et al. 1995, Parris et al. 1999, Corn et al. 2000, Paszkowski et al. 2002, Goldberg and Schwalbe 2004). Biases could be partially mitigated by implementing 2-person observer teams (Nichols et al. 2000, Grant et al. 2005), improving species' identification tapes (Hemesath 1998), incorporating formal training and professional verification (Vandewalle et al. 1996), using automatic sound loggers at wetlands (Parris 2004), and the use of hand-held digital recorders at the time of sampling.

\section{MANAGEMENT IMPLICATIONS}

Our results suggest that incorrect identification of amphibian species in monitoring programs may significantly bias abundance or presence data collected with no assessment of bias, which may prevent the accurate detection of population or abundance trends for which most amphibian monitoring programs were designed. Amphibian monitoring programs should account for omission, commission, and incorrect identification errors.

\section{ACKNOWLEDGMENTS}

This manuscript was improved by comments from $\mathrm{D}$. Fogell, K. Pope, and D. Wardwell. We thank D. Fogell, Southeast Community College, for verifying some amphibian calls. We also thank J. Blum, M. Gedney, J. Haahr, M. Hack, T. LaGrange, J. Laux, M. Morten, K. Neiderklein, J. Sherwood, J. Soper, R. Walters, and S. Whipple. We thank J. Hines, United States Geological Survey Patuxent Wildlife Research Center, for helping with program PRESENCE questions. Funding provided by the Nebraska Game and Parks Commission. The Nebraska Cooperative Fish and Wildlife Research Unit is jointly supported by a cooperative agreement between the United States Geological SurveyBiological Resources Division, the Nebraska Game and Parks Commission, the University of Nebraska-Lincoln, the United States Fish and Wildlife Service, and the Wildlife Management Institute.

\section{LITERATURE CITED}

Bart, J., and J. D. Schoultz. 1984. Reliability of singing bird surveys: changes in observer efficiency with avian density. Auk 101:307-318.

Bishop, C. A., K. E. Pettit, M. E. Gartshore, and D. A. Macleod. 1997. Extensive monitoring of anuran populations using call counts and road transects in Ontario (1992 to 1993). Herpetological Conservation 1:149160.

Blaustein, A. R., D. B. Wake, and W. P. Sousa. 1994. Amphibian declines: judging stability, persistence, and susceptibility of populations to local and global extinctions. Conservation Biology 8:60-71.

Buckley, J., and T. J. C. Beebee. 2004. Monitoring the conservation status of an endangered amphibian: the natterjack toad Bufo calamita in Britain. Animal Conservation 7:221-228.

Conant, R., and J. T. Collins. 1998. A field guide to reptiles and amphibians of eastern and central North America. Houghton Mifflin, New York, New York, USA.

Corn, P. S., E. Muths, and W. M. Iko. 2000. A comparison in Colorado of three methods to monitor breeding amphibians. Northwestern Naturalist 81:22-30.

Crouch, W. B., III, and P. W. C. Paton. 2002. Assessing the use of call surveys to monitor breeding anurans in Rhode Island. Journal of Herpetology 36:185-192.

Funk, W. C., D. Almeida-Reinoso, F. Nogales-Sornosa, and M. R. Bustamante. 2003. Monitoring population trends of Eleutherodactylus frogs. Journal of Herpetology 37:245-256.

Genet, K. S., and L. G. Sargent. 2003. Evaluation of methods and data quality from a volunteer-based amphibian call survey. Wildlife Society Bulletin 31:703-714.

Goldberg, C. S., and C. R. Schwalbe. 2004. Considerations for monitoring a rare anuran (Eleutherodactylus augusti). The Southwestern Naturalist 49: 442-448.

Grant, E. H. C., R. E. Jung, J. D. Nichols, and J. E. Hines. 2005. Doubleobserver approach to estimating egg mass abundance of pool-breeding amphibians. Wetlands ecology and management 13:305-320.

Hemesath, L. M. 1998. Iowa's frog and toad survey, 1991-1994. Pages 206-216 in M. J. Lannoo, editor. Status and conservation of Midwestern amphibians. University of Iowa, Iowa City, USA.

Keitt, T. H., D. L. Urban, and B. T. Milne. 1997. Detecting critical scales in fragmented landscapes. Conservation Ecology 1(1):4. <http://www. consecol.org/vol1/iss1/art4/>. Accessed 15 Oct 2005.

Kline, J. 1998. Monitoring amphibians in created and restored wetlands. Pages 360-368 in M. J. Lannoo, editor. Status and conservation of Midwestern amphibians. University of Iowa, Iowa City, USA. 
Knutson, M. G., J. R. Sauer, D. A. Olsen, M. J. Mossman, L. M. Hemesath, and M. J. Lannoo. 1999. Effects of landscape composition and wetland fragmentation on frog and toad abundance and species richness in Iowa and Wisconsin, U.S.A. Conservation Biology 13:14371446.

Kolozsvary, M. B., and R. K. Swihart. 1999. Habitat fragmentation and the distribution of amphibians: patch and landscape correlates in farmland. Canadian Journal of Zoology 77:1288-1299.

Lehtinen, R. M., S. M. Galatowitsch, and J. R. Tester. 1999. Consequences of habitat loss and fragmentation for wetland amphibian assemblages. Wetlands 19:1-12.

MacKenzie, D. I., J. D. Nichols, G. B. Lachman, S. Droege, J. A. Royle, and C. A. Langtimm. 2002. Estimating site occupancy rates when detection probabilities are less than one. Ecology 83:2248-2255.

McDiarmid, R. W., and M. Donnelly. 1994. Group activities and field trips. Pages 175-182 in W. R. Heyer, M. A. Donnelly, R. W. McDiarmid, L. C. Hayek, and M. S. Foster, editors. Measuring and monitoring biological diversity: standard methods for amphibians. Smithsonian Press, Washington, D.C., USA.

McLaren, M. A., and M. D. Cadman. 1999. Can novice volunteers provide credible data for bird surveys requiring song identifications? Journal of Field Ornithology 70:481-490.

Miaud, C., D. Sanuy, and J. N. Avrillier. 2000. Terrestrial movements of the natterjack toad Bufo calamita in a semi-arid, agricultural landscape. Amphibia Reptilia 21:357-369.

Mossman, M. J., M. Hartman, R. Hay, J. R. Sauer, and B. J. Dhuey. 1998. Monitoring long-term trends in Wisconsin frog and toad populations. Pages 169-198 in M. J. Lannoo, editor. Status and conservation of Midwestern amphibians. University of Iowa, Iowa City, USA.

Munger, J. C., M. Gerber, K. Madrid, M. A. Carroll, W. Peterson, and L. Heberger. 1998. U.S. National Wetland Inventory classifications as predictors of the occurrence of Columbia spotted frogs (Rana luteiventris) and pacific treefrogs (Hyla regilla). Conservation Biology 12:320-330.

Muths, E. 2003. Home range and movements of boreal toads in undisturbed habitat. Copeia 1:160-165.

Nichols, J. D., J. E. Hines, J. R. Sauer, F. W. Fallon, J. E. Fallon, and P. J. Heglund. 2000. A double-observer approach for estimating detection probability and abundance from point counts. Auk 117:393-408.

Parris, K. M. 2004. Environmental and spatial variables influence the composition of frog assemblages in sub-tropical eastern Australia. Ecography 27:392-400.

Parris, K. M., T. W. Norton, and R. B. Cunningham. 1999. A comparison of techniques for sampling amphibians in the forests of south-east Queensland, Australia. Herpetologica 55:271-283.

Paszkowski, C. A., G. Scrimgeour, B. A. Gingras, and S. Kendall. 2002. A comparison of techniques for assessing amphibian assemblages on streams in the western boreal forest. The Canadian Field-Naturalist 116:116119.

Pearman, P. B., A. M. Velasco, and A. Lopez. 1995. Tropical amphibian monitoring: a comparison of methods for detecting inter-site variation in species composition. Herpetologica 51:325-337.
Pellet, J., and B. R. Schmidt. 2005. Monitoring distributions using call surveys: estimating site occupancy, detection probabilities and inferring absence. Biological Conservation 123:27-35.

Pierce, B. A., and K. J. Gutzwiller. 2004. Auditory sampling of frogs: detection efficiency in relation to survey duration. Journal of Herpetology 38:495-500.

Pope, S. E., L. Fahrig, and H. G. Merriam. 2000. Landscape complementation and metapopulation effects on leopard frog populations. Ecology 81:2498-2508.

Sargent, L. G. 2000. Frog and toad population monitoring in Michigan. Journal of the Iowa Academy of Sciences 107:195-199.

SAS Institute. 1999. SAS user's guide: statistics. Version 5 edition. SAS Institute, Cary, North Carolina, USA.

Sauer, J. R., B. G. Peterjohn, and W. A. Link. 1994. Observer differences in the North American Breeding Bird Survey. Auk 111:50-62.

Schmidt, B. R. 2005. Monitoring the distribution of pond-breeding amphibians when species are detected imperfectly. Aquatic Conservation 15:681-692.

Scott, N. J., and B. D. Woodward. 1994. Surveys at breeding sites. Pages 118-125 in W. R. Heyer, M. A. Donnelly, R. W. McDiarmid, L. C. Hayek, and M. S. Foster, editors. Measuring and monitoring biological diversity: standard methods for amphibians. Smithsonian Press, Washington, D.C., USA.

Shirose, L. J., C. A. Bishop, D. M. Green, C. J. MacDonald, R. J. Brooks, and N. J. Heleferty. 1997. Validation tests of an amphibian call count survey technique in Ontario, Canada. Herpetologica 53:312-320.

Skelly, D. K., K. L. Yurewicz, E. E. Werner, and R. A. Relyea. 2003. Estimating decline and distributional change in amphibians. Conservation Biology 17:744-751.

Stevens, C. E., A. W. Diamond, and T. S. Gabor. 2002. Anuran call surveys on small wetlands in Prince Edward Island, Canada restored by dredging of sediments. Wetlands 22:90-99.

Stevens, C. E., and C. A. Paszkowski. 2004. Using chorus-size ranks from call surveys to estimate reproductive activity of the wood frog (Rana sylvatica). Journal of Herpetology 38:404-410.

Trenham, P. C., W. D. Koenig, M. J. Mossman, S. L. Stark, and L. A. Jagger. 2003. Regional dynamics of wetland-breeding frogs and toads: turnover and synchrony. Ecological Applications 13:1522-1532.

Vandewalle, T. J., K. K. Sutton, and J. L. Christiansen. 1996. Pseudacris crucifer: an Iowa case history study of an amphibian call survey. Herpetological Review 27:183-185.

Wear, D. J., D. E. Keil, and R. Altig. 2002. Inter-observer survey comparisons: stream frogs in southeastern Madagascar and a lab test. Herpetological Natural History 9:79-82.

Zampella, R. A., and J. F. Bunnell. 2000. The distribution of anurans in two river systems of a coastal plain watershed. Journal of Herpetology 34: 210-221.

Associate Editor: Block 